\title{
International patent citations and its firm-led network
}

\author{
Jorge Nogueira de Paiva Britto ${ }^{1}$ \\ Leonardo Costa Ribeiro \\ Eduardo da Motta e Albuquerque ${ }^{3}$
}

\begin{abstract}
This paper presents a database with USPTO patents for selected years between 1991 and 2009 , totaling 1,022,490 patents, 786,780 patents with international citations and 4,064, 995 cross-border citations - links in our analysis. We evaluate a network from those international links, with nodes that are institutions - patent assignees. The literature review organizes arguments for patent citations as knowledge flows and acknowledges problems such as differences between applicants and examiners citations - an exercise to deal with this problem is presented. This network has firms as the dominant institution. An inter-temporal analysis shows the network growth over time and the preservation of its scale-free structure, evidence of its resilience. Over time, this network evolves, changing the leading sectors in a matrix of interaction between citing and cited patents - indications of changes caused by the emergence of new sectors.
\end{abstract}

\section{Keywords}

Patent Citations; International Knowledge flows; Innovation Systems

\section{Resumo}

Este artigo apresenta um banco de dados com patentes concedidas pelo USPTO para anos selecionados entre 1991 e 2009: 1.022 .490 patentes, 786.780 patentes com citações internacionais e 4.064.995 citações transfronteiras - links em nossa análise. A rede formada por

- We thank the financial support from CNPq (Grant 307787/2018-4). The authors would like to thank two referees of this Journal - Estudos Econômicos - for their meticulous reading and insightful criticisms, comments and suggestions on two previous versions of this paper. The usual disclaimer holds.

1 Professor - Universidade Federal Fluminense (UFF) - Departamento de Economia.

End.: Rua Alexandre Moura, 8 - Bloco F, São Domingos - CEP: 24210-200 - Niterói - R.J. - Brazil. E.mail: britto.jorge@gmail.com - ORCID: https://orcid.org/0000-0003-0730-4958.

2 Professor - Universidade Federal de Minas Gerais (UFMG) - Cedeplar - Departamento de Ciências Econômicas - End.: Avenida Antônio Carlos, 6.627 - Gabinete 3.133 - Pampulha - CEP: 31270-901 Belo Horizonte - M.G. - Brazil - E-mail: 1cr@cedeplar.ufmg.br ORCID: https://orcid.org/0000-0002-7772-9313.

3 Professor - Universidade Federal de Minas Gerais(UFMG) - Cedeplar - Departamento de Ciências Econômicas - End: Avenida Antônio Carlos, 6.627 - Gabinete 3.069 - Pampulha - CEP: 31270-901 Belo Horizonte - M.G. - Brazil - E-mail: albuquer@cedeplar.ufmg.br

ORCID: https://orcid.org/0000-0002-1591-875X.

Recebido: 15/10/2020 - Aceite: 23/07/2021

Editor Responsável: Dante Mendes Aldrighi

(c) (i) (\$) Esta obra está licenciada com uma Licença Creative Commons Atribuição-Não Comercial 4.0 Internacional. 
esses links internacionais tem como seus nós instituições - titulares das patentes. A revisão da literatura organiza argumentos para investigar citações de patentes como fluxos de conhecimento e reconhece problemas como diferenças entre citações de titulares e examinadores - um exercício para lidar com esse problema é apresentado. Essa rede tem firmas como a instituição predominante. Uma análise intertemporal mostra o crescimento da rede ao longo do tempo e a preservação de sua estrutura sem escala, evidência de sua resiliência. Com o tempo, essa rede evolui, mudando os setores líderes em uma matriz de interação entre patentes que citam e que são citadas - indícios de mudanças ocasionadas pelo surgimento de novos setores.

\section{Palavras-chave}

Patentes; Fluxos internacionais de conhecimento; Sistemas de Inovação

\section{Classificação JEL \\ O32, O34, O39}

\section{Introduction}

This paper investigates a firm-led network of international knowledge flows.

As an ever-changing system, capitalism is becoming more internationalized, which reflects the presence of a greater intensity of cross-border flows, international connections, agents distributed throughout different countries - international or internationally-connected institutions. It is highly probable that the basic economic unit in contemporary capitalism is the multinational firm. And since innovation is a key element in this system, it is also becoming more internationalized.

The internationalization of the economic system is a very uneven process, involving the coexistence of different paces of internationalization. Those uneven rhythms of internationalization can easily be understood by comparing different speeds of internationalization between economic activities (finance, science, production, technology), between industrial sectors, and between countries and regions (there are regions with more international connections and others more isolated and unconnected).

In this paper, our subject is international knowledge flows through patent citations. There are other international knowledge flows that may be investigated using patent data, including at least five different ones: 
assignee-inventor, Global Ultimate Owner (GUO)-assignee, co-inventor, and co-assignee, and cross-border patent citation. Miranda (2014) evaluates three of those international flows (assignee-inventor, co-inventors, and co-assignees), that grew from around 6\% of total patents in 1984 to $12 \%$ in 2009 (data for selected firms in EPO) (Miranda 2014, 95, 110). In a previous manuscript (Ribeiro et al 2016) a comparison between the scope of those different international flows was developed (Patstat data, for Triadic patents): in 2009, the international assignee-inventor flow was $11 \%$ of total patents granted, the flow GUO-assignee $4 \%$, the flow co-inventor $7 \%$, and the flow co-assignee $1 \%$. International patent citations are more expressive: in 2000 a total of $88 \%$ of triadic patents had at least one citation of a foreign patent, and in 2010 that proportion reached 90\%. The scale of this proportion is one of the reasons why this paper chooses patent citations as the topic of our analysis.

Patent citation generates the linkage that is the unit of analysis of our research: an international linkage between institutions located in different countries.

There are three specific questions that we propose to investigate: 1) is there a network of international, cross-border knowledge flows based on patents citations, connecting institutions (firms, universities) of different countries? 2) is this network a complex one? 3) what are the basic features of its evolution?

These three questions organize this paper, in an attempt to contribute to the understanding of peculiar features of this technologically-focused network of international knowledge flows.

This paper is structured in six sections. The first reviews the literature on patent citations to understand how they may be used for investigations of knowledge flows. The second section describes our data and our methodology to investigate international knowledge flows through patent citations. The third section investigates our first question: the existence of a network of international knowledge flows based on patent citations, presenting and describing this network in relation to its nodes (firms and institutions) and its aggregation by countries. The fourth section focuses on our second question: the nature of this network, especially its association to a self-organized complex system. The fifth section relates to our 
third question: the inter-temporal changes of this complex network. The sixth section concludes this paper.

\section{Literature review: patent citations and knowledge flows}

This section presents a literature review to support our basic methodological strategy: the use of patent citations as proxies of knowledge flows. As explained in the Introduction, the unit of analysis of this paper is an international knowledge flow, identified by a cross-border patent citation, that links two institutions - one that cites a patent and another that is cited by that patent.

The literature on patent citations is abundant, and the works of Caballero and Jaffe (1993) and Jaffe, Trajtenberg and Henderson (1993) may be taken as early efforts on this issue. Our methodological strategy focuses our literature review on three basic questions. First, the broad question of how patent citations may be interpreted as a knowledge flow. Second, a more specific question, put forward by a more specialized branch of this literature, that investigates the source of patent references included in the patent document, that may be either the applicant or the examiner. Third, a question related to the international dimension of patent citations.

\subsection{Patent citations and knowledge flows}

Since the seminal analysis from Arrow (1962) on the contradictory role of patents as a source of information and as a monopoly, stocks of patents organized by patent offices (see www.uspto.gov, as an example) may be investigated as a rich source of technological information. Results of patent searches provide free access to this stock of knowledge codified in patent documents.

However, Arrow (1974) also puts forward a very specific cost to use this knowledge: previous investments in knowledge and infrastructure would be necessary to access and understand those stocks of technological information available. This insight is related to a rich literature on absorptive 
capabilities necessary to use this knowledge (Cohen and Levinthal 1989, 1990).

Since Caballero and Jaffe (1993) and Jaffe, Trajtenberg and Henderson (1993), important literature has been developed using patent citations in order to measure knowledge spillovers and as an approximation for knowledge flows. In their paper Jaffe, Trajtenberg and Henderson $(1993,578)$ suggest that "...knowledge flows do sometimes leave a paper trail, in the form of citations to patents". Patent citations are a proxy of how the available stock of knowledge may be used as a source for new patents (Jaffe and Trajtenberg 2002). Patent citations, therefore, contribute to understanding two sets of agents: first, those who generate and "own" knowledge - patent owners (or patent assignees of cited patents) - and, second, those who can learn and use information from that accumulated stock of knowledge to further technological innovation - institutions that use that knowledge and leave tracks of this use in citing patents, the patent assignee of the citing patent. The investigation on patent citations may uncover those two sides of R\&D (Cohen and Levinthal 1989), as firms may invest in R\&D to generate new knowledge (that may lead to a patent) and also invest in R\&D to learn - to understand information accumulated in the stock of patents (that may lead to learning that will create a new patent, now with a citation to previous patents). Those firms that create technology can learn, and firms that learn from other firms can create new technology.

Jaffe and Rassenfosse (2017) present a broad and updated review of uses of patent citation as a research tool. Jaffe and Rassenfosse (2017, 1361) classify research using patent citations in two groups: "One research line uses a variety of citation-based statistics to characterize the inventions, in terms of the magnitude and nature of their impact, relative to the existing pool of knowledge. The other research line focuses on the citations themselves, using them as proxies for knowledge linkages across inventors in order to explore the nature of knowledge flows and the factors that affect those flows" (1361). A special section of that paper reviews "citations as an indicator of knowledge flows" (1366-1367).

We may also distinguish three ways to use patent citations in the study of knowledge flows. The first measures the probability of citations between patents. The second one measures citations between patents, based on the hypothesis that, the more an agent cites another one, the more he uses the knowledge produced by this other one. Finally, the third uses citations 
data in order to build matrices close to those of technological proximity. These ways may be connected to two types of citations:1) Backward citations and 2) Forward citations (OECD 2009, 113-116)

Patent citations constitute an effective tool for assessing the stock of knowledge carried by the patent. The first attempt to use patent citations to proxy knowledge spillovers was made by Jaffe, Trajtenberg and Fogarty (2000). In recent decades, patent citations have been also extensively used as a proxy for measuring technological knowledge linkage (Schmoch 1997; Meyer 2001; Verbeek et al. 2002; Tijsen 2005; Hu et al. 2007; Criscuolo and Verspagen 2008; Britto et al. 2019; Lo 2010; Callaert et al. 2012). The cumulative and path-dependent character of knowledge accumulation can also be associated with the analysis of patent citations, being correlated with some hypotheses detailed in the analysis of Fleming and Sorenson (2004).

Chen (2017, 63-64) presents a good revision of the controversies related to how patent citation may or may not reflect a technological linkage. In his review, the role of applicants and examiners as source of citations is very important for this debate.

\subsection{Examiners' added citations}

The role of applicants and examiners as a source of citation involves different dimensions that affect the nature of the linkage and the knowledge flow. This subsection focuses on the various factors involved, bringing papers that evaluate them and thus contributing to a balanced evaluation.

Alcácer, Gittelman and Sampat (2009) describe the institutional process by which citations are generated and explore three dimensions which could plausibly affect the portion of examiner versus applicant citations in a patent: the technological field of the invention, patent examiner characteristics, and applicant characteristics.

Lemley and Sampat (2012), for instance, demonstrate the presence of an examiner effect, in the sense that more experienced examiners cite less prior art. Alcácer, Gittelman and Sampat (2009) report that the proportion of citations added by examiners is higher for foreign applicants to 
the USPTO; by applicants with a large patent portfolio; and by applicants in electronics, communications, and computer-related fields. They argue that examiner intervention may bias the information content of citations, undermining the use of citations as a measure of knowledge flow, since the inventors may not have even been aware of the patents cited by examiners at the time of invention.

In order to evaluate the role of patent citations as a proxy of knowledge spillovers and as a way to measure technological knowledge connections, Jaffe, Trajtenberg and Fogarty (2000) surveyed US 166 responses of inventors about citing USPTO patents, concluding that patent citations can be interpreted as providing a (noisy) signal of spillovers. They conclude that "the likelihood of knowledge spillovers (...) is significantly greater (...) than the likelihood without a citation (...but...) a large fraction of citations, perhaps something like half, do not correspond to any apparent spillovers (...) citations are a noisy signal of the presence of spillovers" (Jaffe, Trajtenberg and Fogarty 2000, 208). Based on these findings, the authors suggest that aggregate citation flows can be used as proxies for knowledge-spillover intensity, for example, between categories of organizations or between countries.

Considering the use of patent citations as indicators of technology spillovers, and technology flows in a broader sense, Criscuolo and Verspagen $(2008,1982)$ consider that this may be a very indirect use, as citations are "a response to the legal requirement to supply a complete description of the state of the art in the field of the invention". Thus, "citations limit the scope of an inventor's claim to novelty and represent a link to the pre-existing knowledge upon which the invention is built" (Criscuolo and Verspagen 2008, 1892). This characteristic may justify their use as indicators of knowledge spillovers, in a way that an inventor's citing of a patent "may indicate that the knowledge contained in the cited document has been useful in the development of the citing patent, and therefore that the citation might be a proxy for knowledge flow" (Criscuolo and Verspagen $2008,1892)$. However, they are very skeptical in relation to examiner citations, as their "results clearly suggest that it is inventor citations, rather than the total set of citations, that should be taken as indicators of knowledge flows" (Criscuolo and Verspagen 2008, 1908) 
Other papers are less skeptical in relation to those examiner citations. For instance, Jaffe and Rassenfosse $(2019,1370)$ in their broad survey on patent citations mention that "Hegde and Sampat (2009) show that examiner citations have a much stronger relationship with renewal probability (a measure of private value) than the number of applicant citations". Hall et al. (2005), Narin and Noma (1987) and Neuhausler et al. (2011) find a positive correlation between firm performance and the total number of forward citations that their patents receive, even after correcting for firm size. Lanjouw and Schankerman (2004) have determined that patent citations are correlated with other indicators of patent quality. Jaffe et al. (2000) mention that the technical knowledge embodied in the cited patent may reach the citing inventor through a social chain, even if they did not know of the existence of the related patent.

In a very broad evaluation of the literature on this topic, Chen (2017, 63-64) investigates the existence of technological knowledge linkage between patents and their citations measuring text similarities between them. Through the comparison of text similarities between applicant and examiner citing-cited pairs, "the results show that, in more cases, text similarity values of examiner citing-cited pairs are a bit higher than those of applicant citing-cited pairs" (Chen 2017, 76). Chen presents a conclusion that is important for this review: "Compared to applicant citations, logically examiner citations are a good indicator of knowledge linkage rather than an incomplete and noisy indicator. In short, the results suggest that almost certainly patent citations can indicate knowledge linkage, and more likely examiner citations can indicate knowledge linkage a bit better than applicant citations, especially for the component of patent claims. Therefore, we accept the hypothesis that patent citations can indicate knowledge linkage, although a small part of citations represents knowledge linkage incompletely." (76).

\subsection{International patent citations}

Jaffe and Trajtenberg (1999) also pioneered the use of patent citations to understand international flows. Hu and Jaffe (2003) investigated how knowledge diffused from US and Japan to Korea and Taiwan during their catch up processes. This literature provides the foundation for our basic 
unit of analysis - cross-border patent citation as a proxy for an international knowledge flow.

According to Wada (2018), some particularities of international patent citations must also be considered: "[u]nlike the normal citation-generating process, where a citing document confirms the addition of citations to prior art/literature only once at the time of publication, an international patent application has multiple chances to receive patent citations from several examiner" (Wada 2018, 826). In this sense, international patent citations amplify the possibility of capturing relevant knowledge spillovers.

We can also discuss if the aspects that affect the plausibility of using patent citations as a proxy of knowledge spillovers apply equally to national and international patent citations. It is possible to argue that our methodological option for focusing the analysis on international patent citations tends to mitigate the problem, insofar as these patents are subject to a more rigorous evaluation screening, in relation to which a possible "bias" of the analysis tends to be less relevant. Comparing the tendency to cite less localized patents, Alcácer and Gittelman $(2006,778)$ find that between applicant and examiners "there is no significant difference between the distributions. In other cases, examiner citations are more localized than inventor citations". This might suggest that the influence of examiners in the incorporation of citations to patents applies more directly to domestic patents defined at the level of different countries and not to international patents, as considered in this article. In this sense, the "bias" resulting from the performance of examiners in the incorporation of citations to patent documents, reflected in the "noise" provided by this indicator as a "proxy" of knowledge flows, tends to be less significant for our investigation.

As a tool to understand the implications of examiner and applicant citations, this paper devised an exercise to test how those different sources of citations would affect our specific analysis about the properties of the network of patent citations in Section IV. This exercise compares the evolution of the distribution of citations incorporated by applicants and examiners in the case of international patents citations identified in the USPTO database from PATSAT (see APPENDIX BOX 1). 


\section{Data and methodology}

A natural way of representing citation data is in the form of a network. In this sense, researchers have used concepts from network theory to map the structure of knowledge flows based on patent citations. Different studies seek to map the relevance of key components in the structure of the innovation system based on knowledge flows captured from patent citations. Specifically, patent citations may be a very useful tool to characterize the structure of firm-led networks of knowledge flows.

\subsection{Networks}

Patent citations form networks (Breschi and Lissoni 2004). Those networks of patent citations have been investigated by a rich literature (Érdi et al. 2013; Valverde 2014; Valverde et al. 2007). Those investigations evaluate properties of those networks, revealing their growth (Valverde 2014, Figure 2), their frequency distribution over time (Strandburg et al. 2009, 1669), their stratification (Strandburg et al. 2009, 1670), the power law property of those distributions (Valverde 2014, 3), characteristics of specific networks for different products (Valverde 2014) and use of those networks to predict emerging technologies in specific patent classes (Érdi et al. 2013).

International knowledge flows have been investigated as networks (Sorenson et al. 2006). International knowledge flows include networks related to scientific papers (Wagner et al. 2005; Wagner et al. 2015). The properties of those networks were investigated by the pioneering studies that found power law properties and self-organization. Ribeiro et al (2018) integrate this literature, discussing the dynamic growth of networks of scientific international collaboration.

Investigations of properties of networks, especially non-random networks and their self-organization properties, were pioneered by Barabási and Albert (1999), and those tools were used by Wagner et al. (2005) and Valverde (2014) to investigate networks of collaboration in scientific papers and patent citations.

This literature provides the basis for our investigation of networks of international patent citations. From this perspective, the degree of a "node" 
(patent) is simply the number of "connections" (citations) received by the node. Our contribution in this regard is to present a network not yet investigated. The first difference in our network is its link: a cross-border or international patent citation - this is important given the focus of our investigation. A second difference is our definition of node: an institution (patent assignee), that can be a firm, a research institution, a government agency or even individual inventors - all key actors in innovation systems. Since the network investigated in this paper is original, section III presents its description.

\subsection{The source of our database}

The Patstat database was used as a source to provide data needed to build this network. Patstat is organized by the European Patent Office (EPO) and covers almost 70 million patents from more than 100 patent offices around the world, with some of those patents dated as early as the nineteenth century.

For this research we used only data extracted from the USPTO, for two main reasons. First, by choosing one specific patent office we would be analyzing patents granted through the same evaluation and bureaucratic processes - a source of homogeneity. Second, by choosing the US patent office we are using a patent office that sometimes is a proxy for a global patent office, given the size of the US market and the propensity that this induces in institutions (firms, universities, individuals) to file patents there.

The data processing by Patstat provides a broad temporal coverage that is important for this work, as the patents cited are also in this database - a patent granted in 2009 may cite patents from any date prior to 2009. The data collection for our investigation is limited to the first level of citation - we investigated only citations in the patents granted in each selected year (2009, 2006, 2003, 2000, 1997, 1994 and 1991), and at this stage we did not proceed investigating citations in the cited patent. However, patents cited in one year may cite patents from several different years. ${ }^{1}$

1 This is one reason why in Table 1, section III, patents from 2009 cited patents from 151 different countries, although in 2009 patents were granted for only 101 countries. 


\subsection{Steps for our database on international citations}

For the formation of the network to be analyzed in this paper, the node, as already stressed in the Introduction, is the patent assignee (the first patent assignee). The patent assignee as a node allows an analysis of this network investigating the owner of the monopoly rights, the institution that may extract economic income or other competitive advantages from this ownership. This option incurs in problems related to the location of the invention - normally the address of the first inventor -, but since our focus is a knowledge flow, this difference between the assignee country and the inventor country is a source of one specific international flow (see Introduction) that will not be analyzed here.

This focus on patent assignees raises an important research question about the nature of that assignee - what type of institution does it involve: a firm, a university, a government agency?

Since our processing of the database generated a set of patents per year, the second step is to determine if that patent cites patents from assignees from other countries (first patent assignee of the cited patent). If so, those patents are filed, and each citation leads to the link of our investigation an international patent citation. The link, therefore, connects two patents, with two different patent assignees, two different countries - a pair of patent assignees. Those links shape the network that will be investigated, using the tools created by Barabási and Albert (1999).

The data collected in each patent include the sectoral classification of the patent (for the citing and cited patents), according to the USPTO classification. This sectoral classification is an input for the preparation of our matrices of international technology. Those matrices process the original USPTO classes through an algorithm suggested by the Observatoire des Sciences et des Techniques (OST 2006), that aggregates those classes into 30 different technological subdomains (see Appendix Table Al for this list). ${ }^{2}$ Those matrices of international technological flows show how the network that we investigate changes its technological specialization over time.

2 Ribeiro et al (2010) present a matrix for interaction between science and technology, a starting point for the preparation of Figure 1. Britto et al (2020) show matrices of international patent citations, with the same methodology used in this paper, but prepared from a different database (USPTO, not Patstat). 


\section{Question \#1: is there a network of firms and institutions connected by international patente citations?}

An answer to this first question may start by a description of very basic patent data: patents, patents with citations and patents with international citations, as shown in Table 1 below. The number of cited countries also grows, pointing to the growing internationalization - or global reach - of this network. Using Patstat, a database was prepared with USPTO patents for selected years between 1991 and 2009, totaling 1,022,490 patents, 786,780 patents with international citations and 4,064,995 cross-border citations, according to Table 1.

Table 1 - Basic statistics: patents, citations, countries cited and links (1991 - 2009)

\begin{tabular}{rrrrrr}
\hline \multicolumn{1}{l}{ Year } & Patents & Citing Patents & $\begin{array}{c}\text { Inter. Cititing } \\
\text { Patents }\end{array}$ & $\begin{array}{c}\text { Cited } \\
\text { Countries }\end{array}$ & Citations \\
\hline 1991 & 104,981 & 101,486 & 70,390 & 96 & 210,271 \\
1994 & 115,183 & 111,172 & 80,886 & 104 & 276,052 \\
1997 & 133,066 & 127,472 & 93,801 & 114 & 364,997 \\
2000 & 157,545 & 154,104 & 137,102 & 123 & 597,435 \\
2003 & 169,875 & 166,545 & 139,286 & 143 & 757,992 \\
2006 & 174,495 & 171,431 & 132,683 & 146 & 862,952 \\
2009 & 167,345 & 165,769 & 132,632 & 151 & 995,296 \\
\hline
\end{tabular}

SOURCE: PATSTAT, authors' elaboration

There is further confirmation of the internationalization of patent citations in Table 1. In 1991, 67.1\% of the patents cited a patent from abroad, whereas in 2009 this percentage grew to $79.3 \%$. In 2009 the total of patents with international flows was greater than the total of patents in 1994 and almost the same as in 1997. The international reach of this network is also shown in Table 1: in 1991 there were 91 cited countries and in 2009 there were 151 countries.

Since those international flows through patent citations are so generalized, they can form a network connecting different firms and other institutions that patent. The size of this network of international citations totals 4,064,995 links.

This section describes the basic statistics of the network of patent citations. First, it describes its nodes - patent assignees - and the links (international patent citations) that each of them have. Second, those data are rearranged to see how countries aggregate those links. 


\subsection{Firms and institutions as nodes}

In 2009 there were 148,051 different patent assignees - different institutions. The distribution of links (international patent citations) across those nodes is very concentrated: the first 500 nodes have 451,234 links - almost the same total as the remaining 147,551 nodes.

Table 2, data for 2009, shows the 30 leading nodes of this network, according to the total of links (cross-border patent citations) that each node has. Table 2 shows only one type of institution - firms. Given the role of transnational corporations in those flows, according to the framework presented in Britto et al (2013), this ranking is not surprising. Those firms are the leading absorbers of technology through information disclosed in patents.

IBM leads this ranking, with 16,560 cross-border patent citations, to patents from 2,100 different institutions from 47 different countries. Over time, this ranking changes: in 1991 IBM was in the third position, behind Hitachi and Siemens. In 1991, cross-border patent citations connected IBM with 477 institutions from 22 different countries. In a previous paper, Britto et al (2019) describe changes in IBM patent citations, both quantitatively and qualitatively, showing how this transnational corporation increased the number of citations and moved to new technological sectors. ${ }^{3}$

The first university in the ranking presented in Table 2 is the University of California - $62^{\text {nd }}$ position, with 1,198 citations from 34 countries. MIT follows in the $73^{\text {rd }}$ position, University of Princeton in the $216^{\text {th }}$ position and Stanford University is in the $226^{\text {th }}$ position.

3 For a comparison with other networks of international knowledge flows, IBM is at 1,230th position in 2015 in the ranking of institutions with international co-authorships (Ribeiro et al. 2018). The first firm in that ranking is Novartis, which is in the 545th position (with more than 5,000 connections) - Novartis is in the 175 th position in the ranking presented in Table 2. 
Table 2 - Leading nodes (hubs): citing patent assignee name, citations, patents and institutions cited, countries from which they absorb knowledge (2009)

\begin{tabular}{lrrrr}
\hline \multicolumn{1}{c}{ Assignee Name } & \multicolumn{1}{c}{ Citations } & \multicolumn{1}{c}{ Patents } & Institutions & Countries \\
\hline 1 International Business Machines Corporation & 16,560 & 8,763 & 2,100 & 47 \\
2 Hitachi, Ltd. & 16,195 & 10,370 & 3,191 & 46 \\
3 Kabushiki Kaisha Toshiba & 15,637 & 9,262 & 2,658 & 44 \\
4 Fujitsu Limited & 13,179 & 9,072 & 2,505 & 41 \\
5 Samsung Electronics Co., Ltd. & 12,420 & 8,583 & 2,248 & 42 \\
6 Sony Corporation & 11,728 & 7,022 & 2,198 & 45 \\
7 Matsushita Electric Industrial Co., Ltd. & 11,659 & 7,598 & 2,479 & 45 \\
8 Canon Kabushiki Kaisha & 11,194 & 6,398 & 2,019 & 39 \\
9 NEC Corporation & 10,916 & 7,692 & 2,192 & 46 \\
10 Mitsubishi Denki Kabushiki Kaisha & 8,190 & 5,740 & 1,927 & 38 \\
11 Intel Corporation & 6,335 & 3,984 & 1,123 & 39 \\
12 Siemens Aktiengesellschaft & 6,276 & 4,857 & 1,976 & 40 \\
13 General Electric Company & 6,047 & 2,851 & 1,248 & 40 \\
14 Motorola, Inc. & 5,692 & 3,953 & 1,196 & 40 \\
15 Nortel Networks Limited & 5,458 & 3,727 & 1,048 & 29 \\
16 Micron Technology, Inc. & 5,355 & 2,599 & 692 & 30 \\
17 Texas Instruments Incorporated & 4,897 & 3,350 & 975 & 40 \\
18 Eastman Kodak Company & 4,848 & 2,599 & 777 & 37 \\
19 Sharp Kabushiki Kaisha & 4,826 & 3,536 & 1,202 & 34 \\
20 Koninklijke Philips Electronics N.V. & 4,687 & 3,684 & 1,341 & 33 \\
21 Microsoft Corporation & 4,486 & 2,478 & 725 & 41 \\
22 Xerox Corporation & 4,344 & 2,549 & 647 & 38 \\
23 Nokia Corporation & 4,324 & 3,130 & 987 & 31 \\
24 Seiko Epson Corporation & 3,927 & 2,836 & 991 & 33 \\
25 Hewlett-Packard Company & 3,577 & 2,397 & 737 & 35 \\
26 Robert Bosch GmbH & 3,546 & 2,367 & 1,111 & 32 \\
27 Hewlett-Packard Development Company, L.P. & 3,237 & 2,383 & 703 & 33 \\
28 Lucent Technologies Inc. & 3,096 & 2,360 & 790 & 36 \\
29 Telefonaktiebolaget LM Ericsson (publ) & 3,020 & 2,335 & 758 & 26 \\
30 Infineon Technologies AG & 2,947 & 2,303 & 736 & 30 \\
\hline
\end{tabular}

SOURCE: PATSTAT, authors' elaboration

The first government agency in Table 2 ranking is the "United States of America as represented by the Secretary of the Navy", in the $91^{\text {st }}$ position, with 888 international citations, from 37 different countries.

Individual inventors (identified by no assignee name, or by an assignee name equal to the inventor name) are present around the 502th position, with 20 citations.

Table 3 presents another point of observation of this network, focusing on the pairs of institutions that each link connects - it presents a ranking of the leading pairs, showing the two institutions connected by cross-border patent citations. Table 3 also presents only firms as nodes connected in 
those 20 leading pairs. As an evidence that the two sides of R\&D (Cohen and Levinthal 1989) are deeply correlated, four firms are listed in Table 3 as both citing and cited assignee.

The links described in Table 3 suggest that there is also a huge concentration in the distribution of those links. For instance, IBM (as a citing institution) in three links presented in Table 3 concentrates $14.5 \%$ of all its links with connections with only three firms.

Table 3 - Leading links (international patent citations) and its pairs: patent assignee of the citing and cited patent, citations and patents

\begin{tabular}{|c|c|c|c|c|c|}
\hline Citing Assignee Name & Cntry & Cited Assignee Name & Cntry & Citations & Patents \\
\hline 1 Kabushiki Kaisha Toshiba & $J P$ & SanDisk Corporation & US & 1,216 & 162 \\
\hline 2 Micron Technology, Inc. & US & Macronix International Co., Ltd. & TW & 1,053 & 55 \\
\hline 3 Hitachi, Ltd. & $J P$ & International Business Machines Corporation & US & 1,039 & 691 \\
\hline 4 Matsushita Electric Industrial Co., Ltd. & $\mathrm{JP}$ & LG Electronics Inc. & KR & 1,028 & 256 \\
\hline 5 Sony Corporation & $J P$ & Microsoft Corporation & US & 990 & 407 \\
\hline 6 Sony Corporation & $J P$ & LG Electronics Inc. & $\mathrm{KR}$ & 925 & 205 \\
\hline 7 Kabushiki Kaisha Toshiba & $J P$ & Samsung Electronics Co., Ltd. & $\mathrm{KR}$ & 917 & 561 \\
\hline 8 International Business Machines Corporation & US & Samsung Electronics Co., Ltd. & $\mathrm{KR}$ & 878 & 545 \\
\hline 9 International Business Machines Corporation & US & SAP AG & $\mathrm{DE}$ & 874 & 210 \\
\hline 10 Kabushiki Kaisha Toshiba & $J P$ & Micron Technology, Inc. & US & 833 & 368 \\
\hline 11 International Business Machines Corporation & US & Hitachi, Ltd. & $J P$ & 810 & 284 \\
\hline 12 Samsung Electronics Co., Ltd. & $J P$ & Micron Technology, Inc. & US & 770 & 363 \\
\hline 13 General Electric Company & US & Sabic Innovative Plastics IP B.V. & $\mathrm{NL}$ & 729 & 48 \\
\hline 14 Fujitsu Limited & $J P$ & International Business Machines Corporation & US & 719 & 572 \\
\hline 15 Matsushita Electric Industrial Co., Ltd. & $J P$ & Samsung Electronics Co., Ltd. & $\mathrm{KR}$ & 659 & 395 \\
\hline 16 International Business Machines Corporation & US & \multicolumn{2}{|c|}{ Hitachi Global Storage Technologies Netherlands B.' NL } & 645 & 223 \\
\hline 17 Micron Technology, Inc. & US & Samsung Electronics Co., Ltd. & $\mathrm{KR}$ & 634 & 342 \\
\hline 18 Canon Kabushiki Kaisha & $J P$ & Silverbrook Research Pty Ltd & $\mathrm{AU}$ & 632 & 257 \\
\hline 19 Xerox Corporation & US & Silverbrook Research Pty Ltd & $\mathrm{AU}$ & 618 & 281 \\
\hline 20 Kabushiki Kaisha Toshiba & $J P$ & International Business Machines Corporation & US & 617 & 481 \\
\hline
\end{tabular}

SOURCE: PATSTAT, authors' elaboration

Table 4, a ranking of the 21 leading cited patent assignees, also displays only firms in those positions. Those firms are the leading diffusers of technology through information disclosed in their patents.

Among those 21 firms, 10 are also in leading positions as citing patent assignees - an indication of the two faces of R\&D: firms that use other firms' stock of knowledge also provide knowledge to other firms. This phenomenon might also be additional evidence corroborating Rosenberg suggestion that firms would invest their money in basic R\&D as an entry ticket to flows of knowledge (Rosenberg 1990). 
Table 4 - Leading nodes (hubs): cited patent assignee name, citations, patents and institutions citing, countries to which they diffuse knowledge (2009)

\begin{tabular}{lrrrr}
\hline \multicolumn{1}{c}{ Assignee Name } & Citations & Patents & Institutions & Countries \\
\hline 1 Samsung Electronics Co., Ltd. & 23,572 & 3,053 & 5,357 & 42 \\
2 International Business Machines Corporation & 13,162 & 3,622 & 2,931 & 56 \\
3 LG Electronics Inc. & 12,259 & 916 & 2,616 & 43 \\
4 Microsoft Corporation & 12,088 & 2,158 & 2,175 & 55 \\
5 Micron Technology, Inc. & 10,690 & 901 & 1,450 & 38 \\
6 Sony Corporation & 9,177 & 1,383 & 3,833 & 43 \\
7 Silverbrook Research Pty Ltd & 8,089 & 464 & 1,318 & 26 \\
8 Canon Kabushiki Kaisha & 7,558 & 1,624 & 2,864 & 40 \\
9 Panasonic Corporation & 7,333 & 1,474 & 3,267 & 40 \\
10 Fujitsu Limited & 6,887 & 1,104 & 2,677 & 35 \\
11 Kabushiki Kaisha Toshiba & 6,776 & 1,351 & 2,605 & 32 \\
12 Nokia Corporation & 6,741 & 634 & 2,545 & 40 \\
13 Hitachi, Ltd. & 6,722 & 891 & 2,434 & 35 \\
14 Intel Corporation & 5,438 & 1,190 & 1,439 & 37 \\
15 Hewlett-Packard Development Company, L.P. & 5,314 & 1,025 & 1,756 & 44 \\
16 Seiko Epson Corporation & 5,199 & 1,018 & 1,971 & 35 \\
17 SAP AG & 5,059 & 308 & 1,481 & 24 \\
18 Infineon Technologies AG & 5,057 & 577 & 1,802 & 32 \\
19 Siemens Aktiengesellschaft & 4,903 & 667 & 2,492 & 36 \\
20 Semiconductor Energy Laboratory Co., Ltd. & 4,807 & 497 & 1,213 \\
21 Cisco Technology, Inc. & 4,690 & 753 & 863 & 24 \\
\hline
\end{tabular}

SOURCE: PATSTAT, authors' elaboration

\subsection{Aggregating by countries}

Table 5 organizes the data by countries, aggregating the total of cross-border patent citations according to the location of the patent assignee. Developed countries' national systems of innovation lead the ranking - US, Japan, Germany and Canada are the four countries that most intensively access the international stock of knowledge available through patents. Those systems of innovation lead the absorption of technology generated in other countries.

Table 5 shows how recently successful catch-up countries (South Korea and Taiwan) rank well in this regard $-6^{\text {th }}$ and $8^{\text {th }}$ positions, and how China is improving its position (in 2009 in the $20^{\text {th }}$, an advance compared to the $35^{\text {th }}$ position in 1991).

In the ranking shown in Table 5 , the first periphery country - besides China - is in the $29^{\text {th }}$ position: South Africa. Russia $\left(37^{\text {th }}\right)$, Argentina $\left(38^{\text {th }}\right)$, Brazil $\left(39^{\text {th }}\right)$ and Mexico $\left(40^{\text {th }}\right)$ follow. 
Table 5 - Leading assignee countries according to aggregated patent citations: total citations and patents (2009)

\begin{tabular}{|c|c|c|c|}
\hline & $\begin{array}{c}\text { Country of Citing } \\
\text { Assignee }\end{array}$ & Citations & Patents \\
\hline 1 & US & 382.265 & 62.822 \\
\hline 2 & $J P$ & 254.040 & 66.705 \\
\hline 3 & $\mathrm{DE}$ & 71.047 & 34.511 \\
\hline 4 & CA & 41.240 & 23.900 \\
\hline 5 & GB & 32.632 & 19.966 \\
\hline 6 & $\mathrm{KR}$ & 31.629 & 18.755 \\
\hline 7 & $F R$ & 30.889 & 19.124 \\
\hline 8 & TW & 30.240 & 16.116 \\
\hline 9 & SE & 17.532 & 11.318 \\
\hline 10 & $\mathrm{NL}$ & 15.360 & 10.458 \\
\hline 11 & $\mathrm{CH}$ & 14.062 & 9.267 \\
\hline 12 & IL & 11.331 & 7.809 \\
\hline 13 & $\mathrm{FI}$ & 11.248 & 7.190 \\
\hline 14 & IT & 9.735 & 7.009 \\
\hline 15 & $A U$ & 7.000 & 4.960 \\
\hline 16 & DK & 3.585 & 2.394 \\
\hline 17 & BE & 3.462 & 2.681 \\
\hline 18 & SG & 3.386 & 2.889 \\
\hline 19 & AT & 2.343 & 1.804 \\
\hline 20 & $\mathrm{CN}$ & 1.867 & 1.565 \\
\hline 21 & HK & 1.755 & 1.411 \\
\hline 22 & NO & 1.718 & 1.382 \\
\hline 23 & IE & 1.604 & 1.285 \\
\hline 24 & ES & 1.095 & 937 \\
\hline 25 & BM & 1.091 & 862 \\
\hline 26 & LI & 949 & 679 \\
\hline 27 & NZ & 945 & 761 \\
\hline 28 & KY & 944 & 655 \\
\hline 29 & ZA & 939 & 696 \\
\hline 30 & VG & 859 & 726 \\
\hline
\end{tabular}

SOURCE: PATSTAT, authors' elaboration

Table 6 shows the pairs of countries, highlighting how those flows are concentrated among developed countries - there are no periphery countries in the 30 leading pairs. Recently successful catch-up countries (South Korea and Taiwan) are in this list, South Korea and Taiwan citing US patents (respectively pairs number 12 and 13) and South Korea citing Japanese patents (pair number 27). However, both rank higher as sources of knowledge (countries of cited patents, South Korea in positions 6 and 7, Taiwan in positions 10 and 21 ). 
Table 6 - Leading inter-country links (international patent citations) and its pairs: country of the assignee's citing and cited patent, citations and patents (2009)

\begin{tabular}{|c|c|c|c|c|}
\hline & $\begin{array}{c}\text { Country of Citing } \\
\text { Assignee }\end{array}$ & $\begin{array}{c}\text { Country of Cited } \\
\text { Assignee }\end{array}$ & Citations & Patents \\
\hline 1 & $\mathrm{JP}$ & US & 170.239 & 41.878 \\
\hline 2 & US & $J P$ & 117.356 & 25.615 \\
\hline 3 & $\mathrm{DE}$ & US & 47.065 & 21.271 \\
\hline 4 & US & $\mathrm{DE}$ & 43.357 & 7.065 \\
\hline 5 & $\mathrm{CA}$ & US & 31.541 & 17.096 \\
\hline 6 & US & KR & 29.977 & 6.607 \\
\hline 7 & $J P$ & KR & 26.041 & 6.189 \\
\hline 8 & US & CA & 25.516 & 2.274 \\
\hline 9 & GB & US & 23.943 & 13.935 \\
\hline 10 & US & TW & 22.435 & 4.686 \\
\hline 11 & $F R$ & US & 20.970 & 12.210 \\
\hline 12 & TW & US & 17.779 & 8.867 \\
\hline 13 & $\mathrm{KR}$ & US & 16.659 & 9.447 \\
\hline 14 & US & NL & 15.427 & 1.929 \\
\hline 15 & US & $\mathrm{CH}$ & 15.001 & 1.346 \\
\hline 16 & US & FR & 14.826 & 2.563 \\
\hline 17 & US & GB & 14.644 & 1.611 \\
\hline 18 & $J P$ & $\mathrm{DE}$ & 12.382 & 4.368 \\
\hline 19 & US & IL & 11.670 & 842 \\
\hline 20 & SE & US & 11.635 & 7.269 \\
\hline 21 & $J P$ & TW & 9.955 & 3.580 \\
\hline 22 & US & $\mathrm{AU}$ & 9.868 & 897 \\
\hline 23 & $\mathrm{DE}$ & $J P$ & 9.642 & 5.610 \\
\hline 24 & $\mathrm{CH}$ & US & 9.628 & 6.142 \\
\hline 25 & $\mathrm{NL}$ & US & 9.161 & 6.383 \\
\hline 26 & IL & US & 8.440 & 5.601 \\
\hline 27 & KR & $J P$ & 7.707 & 4.981 \\
\hline 28 & US & SE & 7.549 & 1.057 \\
\hline 29 & $\mathrm{FI}$ & US & 6.953 & 4.399 \\
\hline 30 & IT & US & 6.397 & 4.419 \\
\hline
\end{tabular}

SOURCE: PATSTAT, authors' elaboration

Table 6 also show again how the two sides of $R \& D$ are present, as countries in the ranking are listed as citing patents and as with patents cited. The US, for example, is found 12 times in pairs as a country of a citing assignee (absorbing technology) and 13 times as a country of a cited assignee (diffusing technology). 


\section{Question \#2: is this network a complex one?}

After describing the basic statistics of international patent citation as links in this network, the next question is the nature of this network. For this we need to identify the nodes (institutions) and the links (cross-border patent citations) of our network of international patent citations, a preliminary step to investigate its properties, especially its complex structure.

\subsection{Nodes and links - Size and growth of the network}

Table 7 summarizes data regarding size, growth and basic features of this network. Between 1991 and 2009, the number of nodes grew 2.58 times and the total of links grew 4.73 times. The growth of those two components of this network is higher than the growth shown in Table 1 for patents and patents with international citations, respectively 1.58 and 1.88 times. Table 1 also shows that the spread of this network through different countries increased 1.57 times. Those comparisons show that the network has a more intense growth pattern than its basic components - patents and countries involved.

Table 7 - Basic network statistics: nodes, links, average links per node and exponents of the power-law distribution (1991 - 2009)

\begin{tabular}{rrrrc}
\hline Year & \multicolumn{1}{l}{ Nodes } & \multicolumn{1}{l}{ Links } & $\begin{array}{c}\text { Average Links } \\
\text { per Node }\end{array}$ & Exponent \\
\hline 1991 & 57,279 & 210,271 & 3.67 & \\
1994 & 70,573 & 276,052 & 3.91 & 2.06 \\
1997 & 84,982 & 364,997 & 4.29 & 2.09 \\
2000 & 121,884 & 597,435 & 4.90 & 2.09 \\
2003 & 145,475 & 757,992 & 5.21 & 2.06 \\
2006 & 138,965 & 862,952 & 6.21 & 2.06 \\
2009 & 148,051 & 995,296 & 6.72 & 2.03 \\
\hline
\end{tabular}

SOURCE: PATSTAT, authors' elaboration

As the growth of links (international patent citations) is greater than the growth of nodes (institutions, patent assignees), the level of connectiveness of each node also increases, as shown in Table 7: in 1991 there are 3.67 links per node, and in 2009 the number reaches 6.72 links per node. 
The nature of the distribution of those links per node is initially evaluated in the previous section, that highlighted how the leading institutions (mainly firms) concentrated a huge number of links. Those links are also very strong between leading pairs (connections between two nodes of the network), further indicating an uneven distribution of those connections hints of a hierarchical organization of this network. The exponents shown in Table 7 equally suggest a hierarchical organization of this network.

\subsection{Properties of the network: scale-free and self-organization}

The pattern of long-term growth of this network is presented in Graph 1, that investigates that nature of this frequency distribution of links per node, from 1991 to 2009.

Graph 1 shows that the network grows preserving its basic structure. The network displays a power law distribution of connections, in all those years - few nodes (hubs) have many links, many nodes have few links. The identification of this power law distribution highlights the scale-free nature of this network, an indication of its complexity. ${ }^{4}$

At this point we must address one question related to the inclusion of patent citations by examiners. Does this inclusion limit our analysis? Our exercise introduces a checking and control mechanism in the analysis. The result shows that, from the point of view of our investigation, which will focus on the structure of the international patent citation network, it makes no difference if one considers all citations or only those made by the applicants (see APPENDIX BOX 1 and APPENDIX GRAPH Al).

The exponents of those power law distributions are shown in Table 7 relatively constant over time, around 2.05 . This stability suggests the preservation of the hierarchical distribution over time, a feature of this self-organized system that expands - as shown in Tables 1 and 7 -, with more patents, more patents with international citations, more countries cited in patents, more nodes and more links, while preserving its basic structure.

4 For a cleaner expression of those data, the exponents were calculated for all years presented in Table 7, but the Graph shows the curves only for three selected years - 1991, 2000 and 2006. 
The structure of this network of international patent citations is slightly different from the structure described by Valverde (2007, 3; 2014, 3): his network is "neither exponential nor a simple power law" $(2007,3)$. Probably this difference lies in our definition of node - the patent assignee, an institution, predominantly a firm, as shown in section II. Valverde's node is a patent - patents may have many or few citations, but an institution may accumulate many more patents and their citations, reaching a larger order of magnitude.



GRAPH 1 - HISTOGRAM: distribution of patent assignees (nodes) with patent citations according to the number of international patent citations (links) $(1991,2000,2006)$

SOURCE: PATSTAT, authors' elaboration

The network of international patent citations organized by institutions (mainly firms, with an important role for transnational corporations) has properties of scale-free networks, following a simple power law distribution - without deviations -, a characterization that is enough to corroborate its complexity - an important finding to open the doors to further research on the meaning of this international network. 
Self-organization stresses the stability and resilience of this network, thereby its role as a structural feature of contemporary economy.

A key property of scale-free networks is that they are quite robust against random attacks. It comes from not only their hugely heterogeneous connection distribution among the nodes but also the fact that the key role of the hubs on the scale-free network structure is unlikely to randomly pick up a hub to attack, and therefore this significantly alters the dynamic derived from the network (Barabasi 2015, chapter 8). Besides, scale-free networks show the small-world property culminating in the maximum of a 7-neighborhood step to depart from any node and to land on any other node. Due to this property, diffusion processes are very efficient on scale-free networks. Therefore, the merging of robustness and diffusion efficiency reinforces the stability of cross-border links among institutions through patent citations, a knowledge flow with increasingly international characteristics. As such, the investigation of innovation systems requires the inclusion of this structure, this network of international flows. The robustness of this scale-free network underlines how firms (the most important institution in this network) are dependent and reliant on those international flows. And how, for them, national boundaries are always overcome by their capacity to absorb foreign knowledge. Probably, one of the sources of this robustness is that to absorb knowledge, firms create knowledge that diffuses globally.

Scale-free networks are hierarchical. The hierarchy in this firm-led network (power-law exponents around 2.05) is stronger that in the network of international scientific collaboration - a university-led network (power-law exponents around 1,73 ). To use this knowledge, firms must perform $R \& D$ and have internal capabilities to follow, monitor and understand the stock of knowledge accumulated in patents. Those prerequisites are not simple, and they are concentrated in a set of transnational firms with a strong international presence (see Tables 2, 3 and 4). 


\section{Question \#3: what are the basic features of the network's evolution?}

Our investigation so far has shown that this network grows, self-organizes and reproduces its basic and hierarchical structure. The third question is about its long-term evolution and possible changes in its technological specialization.

To investigate this long-term evolution, Figure 1 shows, for selected years, global matrices of technological interaction between cross-border flows among citing and cited patents. Those matrices are organized through the 30 different technological subdomains (see Appendix Table Al for this list) suggested by OST (2006).

An intertemporal comparison between those matrices might show how this self-organized system moves over time. Those matrices evaluate our links - cross-border patent citation - through the investigation of each matrix cell that contains the technological class of the citing patent (x-axis) and the technological class of the cited patent (y-axis). In other words, how the new knowledge (citing patent) is using the stock of knowledge (cited patents). The intensity of this use might be measured by a third axis (z-axis), that shows the number of citations (cross-border patent citations) for that cell - the height of the cell is shown in each matrix.

Over time, the number of cells with international citations has grown the matrix fulfillment grows -, the height of cells grows (see the order of magnitude in the z-axis growing between 1991 and 2009), and the position of the peaks change. Comparing the three matrices in Figure 1, there are movements that differentiate those three snapshots of the network of international patent citations through the lens of technological classes.

There are four main changes in this network over time. ${ }^{5}$

First, the growth in the network and in the number of links is reflected in Figure 1 through the height of z-axis: the leading peak (cell with more citations) was around 0.2 million citations in 1991, 0.6 million citations in 2000 and 1.3 million in 2009.

5 For a broader list of different indicators such as fulfilment indexes, diagonalization indexes, concentration of leading cells, etc, that can be used in the analyses of those matrices, see Britto et al (2019). 
FIGURE 1 - Intersectoral changes in matrices of citing and cited patents (1991, 2000 and 2009)

1991

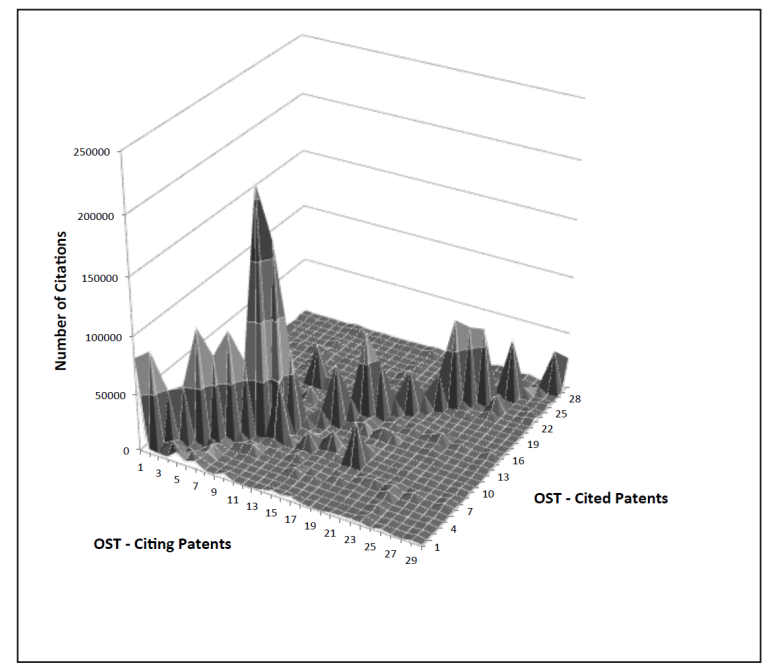

2000

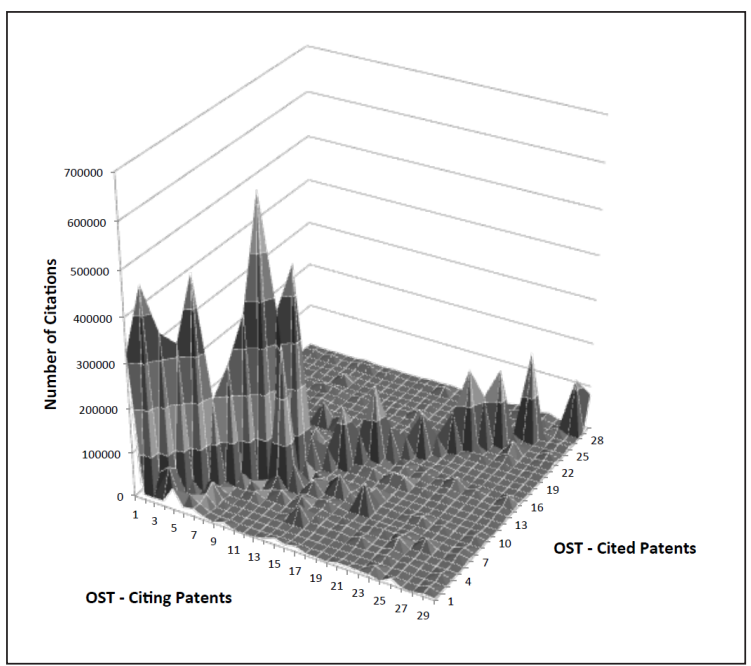

Estud. Econ., São Paulo, vol.51 n.4, p.699-732, out.-dez. 2021 


\section{9}

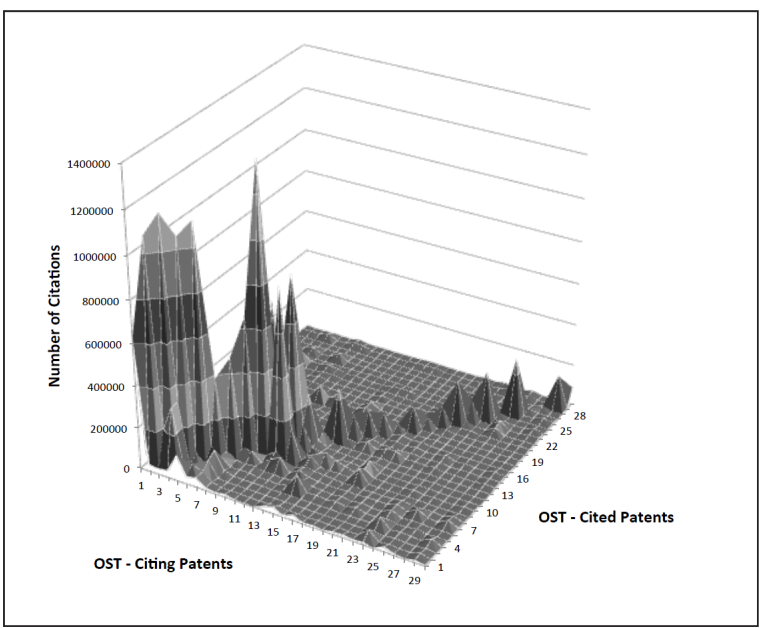

SOURCE: PATSTAT, authors' elaboration - See Appendix Table A.1 for OST Tecnological Subdomains.

Second, over time peaks outside the diagonal become more relevant, as the first non-diagonal peak in 2009 is the $7^{\text {th }}$ position (OST $11 \times$ OST 9), while in 1991 the first non-diagonal peak is in the $21^{\text {st }}$ position (OST 19 $\mathrm{x}$ OST 9). This means a process that suggests that at least for some OST subdomains there is a need to absorb more knowledge from other OST subdomains for their development - a movement towards greater inter-sectoral absorption and diffusion.

Third, there are movements in the ranking of peaks, the leading peaks always occurring with the same OST subdomain as in the citing and in the cited patent. In 1991, the first five peaks are organic fine chemicals (OST 9), macromolecular chemistry (OST 10), semiconductors (OST 5), analysis, measurement and control (OST 7) and audiovisual (OST 2). In 2009 they are organic fine chemicals (OST 9), telecommunications (OST 3), semiconductors (OST 5), audiovisual (OST 2) and information technology (OST 4). In general terms, the movement towards digital technologies is captured by those changes. A finer analysis could be done by focusing on specific cells: for instance, the height of biotechnology (OST 12) in 1991 was $7 \%$ of the leading peak, while in 2009 it grew to $27 \%$ of that peak this could be an indication of new sectors emerging. 
Fourth, the leading OST subdomains in international citing patents (indication of absorption of knowledge) and cited patents (indication of diffusion of knowledge). In 2009, the leading OST subdomains for absorption (sectors in citing patents) are organic fine chemicals (OST 9), information technology (OST 4), pharmaceuticals (OST 11) and telecommunications (OST 3). The ranking of leading OST subdomains for diffusion (sectors in cited patents) are organic fine chemicals (OST 9), audiovisual (OST 2), information technology (OST 4) and telecommunications (OST 3).

This introductory analysis of those matrices shown in Figure 1 highlights movements within this network over time. It also contributes to uncover in what directions this self-organizing system is moving, how it changes in the long term - probably a consequence of structural changes related to technological revolutions and the emergence of new general purpose technologies (GPTs) during those years.

\section{Concluding remarks}

This paper presents a database that can be used as a source for creating a network of cross-border patent citations. This would seem a novel contribution to the matter, since this network has not been investigated so far: the links of the network are international patent citations and the nodes are institutions (the patent assignees).

The answers to the three questions that organize this paper show that 1 ) there is a network of international patent citations, a network that grows over time and that is led by firms; 2) this network is complex (scale-free) and robust; 3) this network over time shows changes in leading sectors and ranking of technological areas.

The identification of this network of international patent citations shows how international knowledge flows connect institutions of different countries in the process of technological learning and innovation. The nature of this network can be defined as a firm-led network, that grows, both in the number of links and nodes. This network displays unevenness among its nodes, as some nodes become hubs of the network. 
In general, complex networks are associated with self-organized systems representing many complex properties of those systems. The association with self-organized systems and the robustness of this network have an important implication on its nature, as it shows that this network is not a transient or short-term phenomenon. The uneven structure of the network is hierarchical, and this hierarchy indicates its scale-free property. As a complex and robust network it is protected from localized failures. It means that this network has a capacity to survive and that it may be analyzed as a structure in itself.

This complex network shows its plasticity in relation to technological change, as their matrices of technological sectors show three long-term movements: the spread over a larger number of sectors, the strengthening of new sectors with new leading sectors and new rankings of leading sectors.

There are implications for public policy.

This network of international knowledge flows is a source of opportunity, since the stock of patented knowledge is available to every institution in the world. Firms in less developed countries can access this knowledge, as well as new firms in developed countries. This stock of knowledge has been a source of transformation of older firms that may tap into this stock of knowledge to move into new and emerging systems. The stability, growth and robustness of this network suggest that the access to those international knowledge flows can be a goal in the planning of activities of firms, institutions and countries - innovation systems can be enriched by access to those flows.

However, the hierarchical nature of this network poses great challenges to firms and institutions on the periphery and to new firms at the center. The preconditions to join this network are increasing, as the scientific and technological bases of new technologies expand. The stability of this network over time poses special challenges for institutions on the periphery. The database shows that the network grows over time - this means that more countries join the network, a process that broadens the set of countries that may absorb and diffuse knowledge. The network also changes over time, expanding in different sectors in different moments, a process that may open new opportunities. Since 1991 this very hierarchical network involved a systematic upgrade of the position of two countries - 
South Korea and Taiwan, which are now among the five leading countries (Table 5) - and includes an initial and sustained upward movement of China, reaching the 19th position in 2009.

The networks of international knowledge flows described in this paper shows challenges, opportunities and changes for countries at the periphery, so they may be an important topic in a research agenda on future catch up processes.

This research agenda can address current limitations in our analysis. First, the issues related to applicants versus examiners citations may be further investigated through the technique employed in our exercise presented in Appendix Box 1. Second, other techniques to investigate other indications of interactions between citing and cited patents may be developed: patent inventors are researchers that participate in science and engineering international communities that have different forms of interaction in conferences, meetings and through labor mobility. ${ }^{6}$ Third, a deeper investigation of the forces behind the growth and evolution of this firm-led international network to understand its long term dynamics.

\section{References}

Alcácer, Juan. and Michelle Gittelman. 2006. "Patent citations as a measure of knowledge flows: the influence of examiner citations." Review of Economics and Statistics 88, no. 4: 774-779. https://doi.org/10.1162/rest.88.4.774.

Alcácer, Juan, Michelle Gittelman, and Bhaven Sampat. 2009. "Applicant and examiner citations in U.S. patents: an overview and analysis." Research Policy 38, no. 5: 415-427. http://dx.doi.org/ 10.1016/j.respol.2008.12.001.

Arrow, Kenneth. 1962. "Economic welfare and the allocation of resources for invention". In The rate and direction of inventive activity, edited by Richard Nelson, 609-626. Princeton: Princeton University Press.

Arrow, Kenneth. 1974. The limits of organisation. New York: W. W. Norton \& Co..

6 One suggestion is an investigation tracing how patent inventors from different firms might interact in international conferences and become familiar with technological and scientific developments within different firms' research teams. For example: Table 3 shows the international links between Sony and Microsoft. Those links may be illustrated by USPTO patent number 7,924,913 (from Microsoft, with G. Sullivan as an inventor) that cites USPTO patent number 6,463,445 (from Sony, Japan, with T. Suzuki as an inventor), and one 2007 IEEE INTERNATIONAL CONFERENCE ON IMAGE PROCESSING paper - "New standardized extensions of MPEG4-AVC/H.264 for professional-quality video applications" - that is co-authored among others by G. Sullivan and T. Suzuki. Such very preliminary finding might indicate other less straight forms of interaction between a researcher citing a patent from a researcher that he/she met in international meetings or conferences - those might be previous interactions between researchers that are patent inventors before a patent citation. 
Barabási, Albert-László, Réka Albert. 1999. "Emergence of scaling in random networks". Science, v. 286, no. 5439: 509-512. https://doi.org/10.1126/science.286.5439.509

Breschi, Stefano, Francesco Lissoni. 2004. "Knowledge networks from patent data". In Handbook of quantitative science and technology research, edited by Henk Moed, Wolfgang Glänzel, and Ulrich Schmoch, 613-643. Dordrecht: Kluwer Academic Publishers.

Britto, Gustavo, Otávio Camargo, Glenda Kruss, Eduardo da Motta e Albuquerque. 2013. "Global interactions between firms and universities". Innovation and Development 3, no. 1: 71-88. https://doi.org/10.1080/215793 $\underline{0 X .2012 .762169}$

Britto, Jorge.; Leonardo Costa Ribeiro, Lucas Teixeira Araújo, Giulia Tonon da Matta Machado, Eduardo da Motta e Albuquerque. 2019. 'Knowledge flows, changing firms' competences and patent citations: an analysis of the trajectory of IBM". Economics of innovation and new technology 28, no. 4: 317-347. https://doi.org/10. $\underline{1080 / 10438599.2018 .1496602}$

Britto, Jorge.; Leonardo Costa Ribeiro, Lucas Teixeira Araújo, Eduardo da Motta e Albuquerque. 2020. "Patent citations, knowledge flows and catching-up: evidences of different national experiences for the period 1982-2006". Science and Public Policy 47, no. 6: 788-802. https://doi.org/10.1093/scipol/scaa041.

Caballero, Ricardo J., Adam B. Jaffe. 1993. “How High are the Giants' Shoulders: An Empirical Assessment of Knowledge Spillovers and Creative Destruction in a Model of Economic Growth". National Bureau of Economic Research Working Paper Series, No. 4370. https://doi.org/10.3386/w4370

Callaert, Julie, Joris GROUWELS, and Bart Van LOOY. 2012. "Delineating the scientific footprint in technology: Identifying scientific publications within non-patent references." Scientometrics 91, no. 2: 383-398. https://doi. org/10.1007/s11192-011-0573-9

Chen, Linxin. 2017. "Do patent citations indicate knowledge linkage? The evidence from text similarities between patents and their citations." Journal of Informetrics 11, no. 1: 63-79. https://doi.org/10.1016/j.joi.2016.04.018.

Cohen, Wesley M., and David A. Levinthal. 1989. "Innovation and Learning: the two faces of R\&D." The Economic Journal 99, no. 397: 569-596. https://doi.org/10.2307/2233763.

Cohen, Wesley M., and David A. Levinthal. 1990. "Absorptive capacity: a new perspective on learning and innovation”. Administrative Science Quarterly 35, no. 1: 128-152. https://doi.org/10.2307/2393553.

Criscuolo, Paola, Bart Verspagen. 2008. "Does it matter where patent citations come from? Inventor vs. examiner citations in European patents”. Research Policy 37, no. 9: 1892-1908. https://doi.org/10.1016/j.respol.2008.07.011

Duguet, Emmanuel, Megan MacGarvie. 2005. "How well do patent citations measure ows of technology? Evidence from French innovation surveys". Economics of Innovation and New Technology 14, no. 5: 375-393. https://doi.org/10.1080/1043859042000307347

Érdi, Péter, Kinga MAKOVI, Zóltan SOMOGYVÁRI, Katherine STRANDBURG, Jan TOBOCHNIK, Péter VOLF, and ; László ZALÁNYI. 2013. "Prediction of emerging technologies based on analysis of the U.S. patent citation network.” Scientometrics 95, no. 1: 225-242. https://doi.org/10.1007/s11192-012-0796-4.

Fleming, Lee, Olav Sorenson. 2004. "Science as a map in technological search." Strategic Management Journal 25, no. 8-9: 909-928. https://doi.org/10.1002/smj.384.

Guellec, Dominique, Bruno de la Potterie. 2004. "Measuring internationalization of the generation of technology: an approach based on patent data." In Handbook of quantitative science and technology research, edited by Henk Moed, Wolfgang Glänzel, and Ulrich Schmoch, 645-662. Dordrecht: Kluwer Academic Publishers.

Hegde, Deepak, Bhaven Sampat. 2009. "Examiner citations, applicant citations, and the private value of patents." Economics Letters 105, no. 3: 287-289. https://doi.org/10.1016/j.econlet.2009.08.019.

Hu, Dainig, Hsinchun Chen, Zan Huang, Mihail Roco. 2007. "Longitudinal study on patent citations to academic research articles in nanotechnology (1997-2004).” Journal of Nanoparticle research 9, no. 4: 529-542. https:// doi.org/10.1007/s11051-007-9215-9 
Hu, Albert G. Z; Adam B. Jaffe. (2003) "Patent citations and international knowledge flows: the cases of Korea and Taiwan". International Journal of Industrial Organization 21, no. 6: 849-880. https://doi.org/10.1016/ S0167-7187(03)00035-3.

Jaffe, Adam B., Manuel Trajtenberg, Rebecca Henderson. 1993. "Geographic Localization of Knowledge Spillovers as Evidenced by Patent Citations". The Quarterly Journal of Economics 108, no. 3:577-598. https://doi. org/10.2307/2118401.

Jaffe, Adam B., Manuel Trajtenberg. 1999. "International Knowledge Flows: Evidence from Patent Citations." Economics of Innovation and New Technology 8, no. 1-2: 105-136. https://doi.org/10.1080/10438599900000006.

Jaffe, Adam B., and Manuel Trajtenberg. 2002. Patents, Citations, and Innovations: a window on the knowledge economy. Cambridge, MA/London: MIT Press.

Jaffe, Adam B., and Gaétan de Rassenfosse. 2017. "Patent Citation Data in Social Science Research: Overview and Best Practices." Journal of the Association for Information Science And Technology 68, no. 6: 1360-1374. https://doi.org/10.1002/asi.23731.

Jaffe, Adam B., Manuel Trajtenberg, and Michael Fogarty. 2000. "Knowledge spillovers and patent citations evidence from a survey of inventors." American Economic Review 90, no. 2: 215-218. https://doi.org/10.1257/ aer.90.2.215

Lanjouw, Jean, Mark Schankeman. 2004. "Patent quality and research productivity: measuring innovation with multiple indicators.” Economic Journal 114, no. 495: 441-465. https://doi.org/10.1111/j.1468-0297.2004.00216.x.

Lemley, Mark, Bhaven Sampat. 2012. "Examiner characteristics and patent office outcomes." Review of Economics and Statistics 94, no. 3: 817-827. http://www.jstor.org/stable/23261480.

Leydesdorff, Loet, Caroline Wagner. 2008. "International collaboration in science and the formation of core group.” Journal of Informetrics 2, no. 4: 317-325. https://doi.org/10.1016/j.joi.2008.07.003.

Linden, Greg, Kenneth Kraemer, Jason Dendrick. 2007. "Who captures value in a Global Innovation System? The case of Apple's iPod.” Communications of the ACM 52, no. 3: 140-144. https://doi.org/10.1145/1467247.1467280.

Lo, Szu-chia S. 2010. "Scientific linkage of science research and technology development: a case of genetic engineering research." Scientometrics 82, no. 1: 109-120. https://doi.org/10.1007/s11192-009-0036-8

Meyer, Martin. 2001. "Patent citation analysis in a novel field of technology: An exploration of nano-science and nano-technology”. Scientometrics, 51 no. 1: 163-183. https://doi.org/10.1023/A:1010572914033.

Miranda, Pedro. 2014. “A internacionalização das atividades tecnológicas e a inserção dos países em desenvolvimento: uma análise baseada em dados de patentes.” Campinas: Unicamp (Tese de Doutorado). http://repositorio. unicamp.br/jspui/bitstream/REPOSIP/286442/1/Miranda_PedroCarvalhode_D.pdf.

Observatoire des Sciences et des Techniques (2006). Science \& Technologie: indicateurs 2006. Paris: Economica. http://www.obs-ost.fr/le-savoir-faire/etudes-en-ligne/etudes-2006/rapport-2006.html.

OECD. 2009. “OECD Patent Statistics Manual”. Paris: OECD. https://doi.org/10.1787/9789264056442-en.

Patel, Parimal. 1995. "Localised production of technology for global markets". Cambridge Journal of Economics 19, no. 1: 141-155. https://doi.org/10.1093/oxfordjournals.cje.a035300

Powell, Walter W., Stine Grodal. 2005. "Networks of innovators." In: The Oxford Handbook of Innovation, edited by Jan Fagerberg, David Mowery, and Richard R. Nelson, 56-85, Oxford: Oxford University Press.

Ribeiro, Leonardo Costa, Ricardo Machado Ruiz, Américo Tristão Bernardes, Eduardo da Motta e Albuquerque. 2010. "Matrices of science and technology interactions and patterns of structured growth: implications for development". Scientometrics 83, no. 1: 55-75. https://doi.org/10.1007/s11192-009-0020-3

Ribeiro, Leonardo Costa, Leandro Alves Silva, Márcia Siqueira Rapini, Gustavo Britto, Eduardo da Motta e Albuquerque. 2016. "Mapping international knowledge flows: three dimensions for a framework to evaluate transnational cooperation in research". Paper presented at the conference The Transformation of Research in the South: policies and outcomes (Paris, 21 and 22 January 2016). Paris: IDRC/IRD/OECD Development Centre. http://ifris.org/wp-content/blogs.dir/1/files/2016/01/Eduardo-Albuquerque-MAPPING-INTERNATIONAL-KNOWLEDGE-FLOWS.pdf. 
Ribeiro, Leonardo Costa, Leandro Alves Silva, Márcia Siqueira Rapini, Eduardo da Motta e Albuquerque. 2018. "Growth patterns of the network of international collaboration in science". Scientometrics 114, no. 1: 159-179. https://doi.org/10.1007/s11192-017-2573-x

Rosenberg, Nathan. 1990. "Why do firms do basic research (with their money)?" Research Policy 19, no. 2: 165-174. https://doi.org/10.1016/0048-7333(90)90046-9.

Schmoch, Ulrich. 1997. "Indicators and the relations between science and technology." Scientometrics 38, no. 1: 103-116. https://doi.org/10.1007/BF02461126

Sorenson, Olav, Jan W. Rivkin, Lee Fleming. 2006. "Complexity, networks and knowledge flow". Research Policy 35, no. 7: 994-1017. https://doi.org/10.1016/j.respol.2006.05.002

Strandburg, Katherine J., Gabor Csardi, Jan Tobochnik, and Peter Erdi. 2009. Patent citation networks revisited: signs of a twenty-first century change? North Carolina Law Review 87, no. 5: 1657-1698. https://ssrn.com/ abstract $=1413290$.

Tijsen, Robert. (2005). "Measuring and evaluating science-technology connections and interactions." In Handbook of quantitative science and technology research, edited by Henk Moed, Wolfgang Glänzel, and Ulrich Schmoch, 695-715. Dordrecht: Kluwer Academic Publishers.

Valverde, Sergi. 2014. "Evolution of patent citation networks," 2014 Complexity in Engineering (COMPENG): 1-5. https://doi.org/10.1109/CompEng.2014.6994688

Valverde, Sergi, Richard V. Solé, Mark A. Bedau, Norman Packard. 2007. "Topology and evolution of technology innovation networks". Physical Review E 76, no. 5: 056118.1-056118.7. https://doi.org/10.1103/PhysRevE.76.056118.

Verbeek, Arnold, Koenraad Debackere, Marc Luwel, Edwin Zimmerman, and Filip Deleus. 2002. "Linking science to technology: Using bibliographic references in patents to build linkage schemes." Scientometrics 54, no. 3: 399-420. https://doi.org/10.1023/A:1016034516731

Wada, Tetsuo. 2018. "The choice of examiner patent citations for refusals: evidence from the trilateral offices." Scientometrics 117, no. 3: 825-843. https://doi.org/10.1007/s11192-018-2885-5.

Wagner, Caroline, Loet Leydesdorff. 2005. "Network structure, self-organization, and the growth of international collaboration in science." Research Policy 34, n. 10: 1608-1618. https://doi.org/10.1016/j.respol.2005.08.002.

Wagner, Caroline, Han Woo Park, Loet Leydesdorff. 2015. "The continuing growth of global cooperation networks in research: a conundrum for national governments.” PLOS one,10, no. 7: e0131816. https://doi.org/10.1371/ journal.pone. 0131816 .

\section{APPENDIX:}

\section{Appendix box 1: Patents citations included by examiners and our analysis}

This Box addresses one question related to the inclusion of patent citations by examiners. Does this inclusion limit our analysis presented in Sub-section IV.2? As an answer to a suggestion presented by Alcácer, Gittelman and Sampat (2009), this Box introduces a checking and control mechanism in the analysis. This exercise is an answer to the question that 
motivates this Box - and it also could represent a contribution of this paper to the literature review presented in Section I.

This exercise compares the evolution of the distribution of citations incorporated by applicants and examiners in the case of international patents citations identified in the USPTO database from PATSAT.

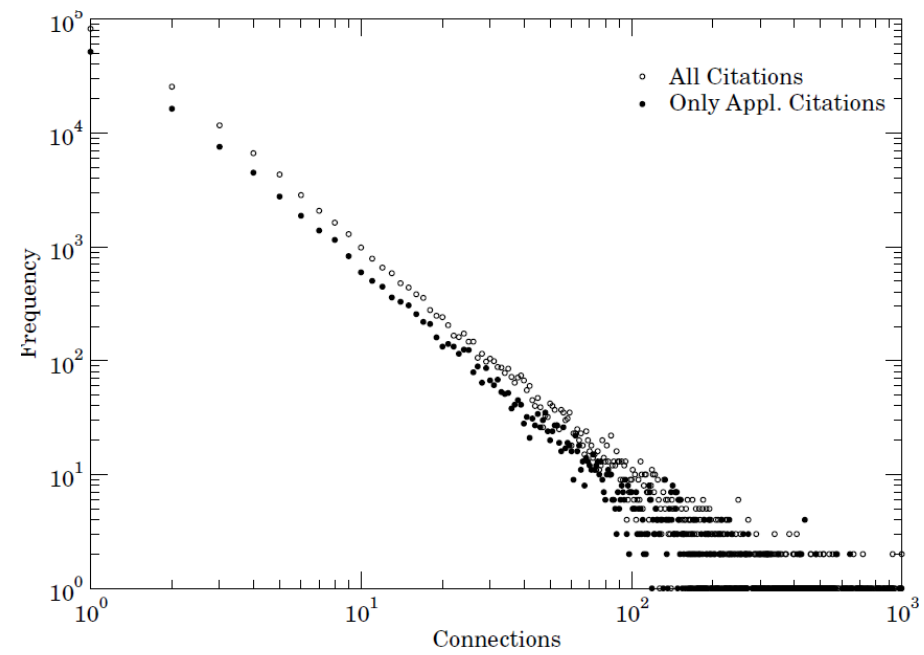

APPENDIX GRAPH Al HISTOGRAM: distribution of patent assignees (nodes) with patent citations according to the number of international patent citations (links) - a comparison between a network with all citations and a network with only the applicant citations (2006)

SOURCE: PATSTAT, authors' elaboration

Appendix Graph Al summarizes our comparison. Since our use of patent citations is directly related to the analysis of the network structure, we prepare an exercise to test how the use of different types of citation would affect our results.

Using the data on the source of the citations available on PATSTAT, we compare two sets of data: one with patent citations added by the applicants and the other with all patent citations - therefore including also the patents added by examiners, as we did in Graph 1. 
This comparison is feasible because the PATSTAT provides one status that identifies the citations made by the applicants. Using this information, another international patent citation network was built using almost the same procedure as before (for Graph 1).

Appendix Graph Al compares those two structures - one with only citations from applicants, the other with all citations. As Appendix Graph Al shows, both have the same exponent and therefore exactly the same structure.

This result shows that, from the point of view of our analysis, which focuses on the structure of the international patent citation network, it is indifferent to consider all citations or only those made by the applicants.

APPENDIX TABLE Al - LIST OF OST Technological subdomains

\begin{tabular}{|c|c|}
\hline OST codes & OST names \\
\hline 1 & Electrical components \\
\hline 2 & Audiovisual \\
\hline 3 & Telecommunications \\
\hline 4 & Information technology \\
\hline 5 & Semiconductors \\
\hline 6 & Optics \\
\hline 7 & Analysis, measurement and control \\
\hline 8 & Medical engineering \\
\hline 9 & Organic fine chemicals \\
\hline 10 & Macromolecular chemistry \\
\hline 11 & Pharmaceuticals and cosmetics \\
\hline 12 & Biotechnology \\
\hline 13 & Agricultural and food products \\
\hline 14 & Technical procedures \\
\hline 15 & Surface technology and coating \\
\hline 16 & Material processing \\
\hline 17 & Materials and metallurgy \\
\hline 18 & Thermal techniques \\
\hline 19 & Basic chemical processing \\
\hline 20 & Environment and pollution \\
\hline 21 & Machine tools \\
\hline 22 & Engines, pumps and turbines \\
\hline 23 & Mechanical components \\
\hline 24 & Handling and printing \\
\hline 25 & Agricultural and food machinery \\
\hline 26 & Transport \\
\hline 27 & Nuclear engineering \\
\hline 28 & Space technology and weapons \\
\hline 29 & Consumer goods and equipment \\
\hline 30 & Civil engineering and building \\
\hline
\end{tabular}

SOURCE: OST (2006)

Estud. Econ., São Paulo, vol.51 n.4, p.699-732, out.-dez. 2021 